\title{
Limits of Using the Results of Polygraph Testing in Criminal Procedure
}

\author{
${ }^{1}$ Sergey F. Shumilin, ${ }^{2}$ Elena A. Kupryashina, ${ }^{* 3}$ Ekaterina A. Novikova, ${ }^{4}$ Vasily J. Potapov, \\ ${ }^{5}$ Andrey V. Stepanyuk \\ ${ }^{1,3}$ Belgorod Law Institute of the MIA of Russia named after I.D. Putilin, 71 Gorky Street, Belgorod, 308024, Russia \\ 2,5 Belgorod State University, 85 Pobedy Street, Belgorod, Belgorod Region, 308015, Russia \\ ${ }^{4}$ Pitirim Sorokin Syktyvkar State University, 55, Oktyabrsky Prospect, Syktyvkar, The Komi Republic, 167001 \\ Russia \\ Email:*novikova_a@bsu.edu.ru
}

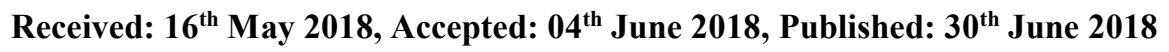

\begin{abstract}
An offer for restrictions, concerning the limits of use of polygraph testing results as orientation information at pre-trial stages of criminal proceedings, was made in this article. Given proposal was based on the study of judicial practice in criminal cases, literature and experience in establishing the criteria of evidence use in the US legislation, received on the background of scientific data.
\end{abstract}

Keywords: Criminal Procedure, Polygraph Testing, Legislative Regulation, Problems of Results Reliability, Limits of Use.

\section{Introduction}

Polygraph testing in the criminal procedure, as shown by the study of literature and investigative practice, is conducted mainly to verify the testimony of suspects, victims and witnesses of crimes, if there is any doubt about the reliability or completeness of the information, reported by them. In this case, polygraph testing of crime suspects often ends with their admission of offence.

At the same time, there are many examples of recognition the false positive conclusions of polygraph operators - truthful answers of tested person are recognized as false - as evidences, and based on them criminal prosecution of the innocents. Such situations are described in the scientific literature, and sometimes they are the subject of discussion in the media.

Taking into account, that polygraph testing can create the prerequisites for violation of the right to personal integrity and the grounds for criminal prosecution of the innocents, the question of establishing the limits of use of polygraph testing results in the criminal procedure is of immediate interest.

\section{Methodology}

General scientific methods of logical cognition are used in the work: analysis, synthesis and generalization. To achieve the set goal, private methods were also used: historical-legal, comparativelegal, formal-logical and content-analysis.

\section{Discussion and Result}

The study of scientific works, dedicated to the application of polygraph in criminal procedure, leads to the conclusion that the polygraph testing results are most often used at the pre-trial stages. In this case such results are used as orientation information (Belgium, Hungary, Israel, Canada, South Korea, etc.).

In some countries, under certain conditions, the results of polygraph testing are used as judicial evidence. For example, in Japan such results are used by lower courts as evidence without any restrictions, and in the Supreme Court - at the judge discretion. In India, the results of polygraph testing are used as evidence only when testing was conducted by civilians, not by police or court personnel.

In the criminal process of Russia and the United States, the results of polygraph testing are used both in the pre-trial proceedings and in the court proceedings, but mechanism for establishing limits for their usage has significant differences.

In Russia, the use of polygraph testing results is not regulated by the criminal procedure law. The instructions of special Departments and Services provide for the use of polygraph testing results only in the pre-trial procedure, and only as orientation information. In fact, such results are submitted to the court as evidence.

Courts of the first instance either do not recognize the results of polygraph testing as evidence, or refer to them in sentences as to evidence, proving the testimony of previously questioned participants of criminal proceeding. Higher courts, considering criminal cases, usually exclude from the sentences references to the results of polygraph testing, indicating that they are not evidence.

The uncertainty of evidential significance of polygraph testing results, and hence the limits of their use in the criminal process of Russia, need to be worked out. To do this, it is reasonable to use the experience of foreign countries in resolving of similar issues. From our point of view, the experience of the 
United States is of particular interest. There, the attempts to establish criteria for using the results of polygraph testing have been made since 1923 .

The limits of using the results of polygraph testing in the criminal process of the United States are established by state laws and federal legislation. Information, obtained from the works on this issue, indicates that, in accordance with the laws of different states, the results of polygraph testing as evidence in court: a) are not used; b) are used without restrictions; c) are used, if it has been stipulated in advance in the written agreement of the prosecution and defense parties.

Federal law, as a rule, establishes criteria for the use of evidence, obtained on the basis of special knowledge (scientific data), and these criteria are extended, including the results of polygraph testing. The establishment of criteria is preceded by the creation of a standard (precedent) for the use of any evidence and its practical application by courts.

In this regard, the establishment of criteria for using the results of polygraph testing by federal legislation of the United States passed the following stages.

In 1923, the Frye standard was created in the judicial practice of the US. It was named after the accused Frye, who tried to present to the district court the testimony of polygraph operator, that the test results witnessed his innocence. However, the court did not accept this evidence and did not allow re-testing, motivating the decision by the lack of reliable principles for conducting polygraph testing, which would be recognized by authoritative scientists in the field of psychology and physiology. The Supreme Court of the District of Columbia upheld the decision of the District Court.

Consequently, the standard for the use of evidence was developed. It states, that the information, based on scientific knowledge, can be admitted as evidence, if they are recognized in the relevant field of science [1]. Practically, the Frye standard restricted the use of test results in the pre-trial proceedings, where the police could use them for detection of crimes.

According to the published decisions of the US Supreme Court and the Supreme Courts of some states, the Frye standard was not adopted by all courts, and where it was adopted, it was significantly interpreted in the process of hearing of specific criminal cases.

In January 1975, the US Congress adopted the Federal Rules of Evidence. It contains, inter alia, the rule 702, "Testimony by Experts": If scientific, technical, or other specialized knowledge will assist the trier of fact to understand the evidence or to determine a fact in issue, a witness qualified as an expert by knowledge, skill, experience, training, or education, may testify thereto in the form of an opinion or otherwise [2].
In 1993, the Supreme Court of the USA created the Daubert standard. It states, that the standard, according to which the achievements in the field of science, with the help of which the evidence is obtained, should be universally recognized in the relevant scientific field, is not so important (emphasized by the authors), such as whether the expert's testimony can help the judge and jurors to understand the actual circumstances of the case. When resolving this issue, the court must take into account the following circumstances: 1) whether the data of science and technology are verified, with the help of which the evidence is obtained; 2) whether these data are checked by the scientific community; 3 ) the known or potential rate of error, when using this data; 4) whether these data are confirmed by the scientific community [3].

The application of the Daubert standard in practice served as the basis for the amendment of rule 702 of the Federal Rules of Evidence in 2000 and 2011 . Now it is the following:

"A witness who is qualified as an expert by knowledge, skill, experience, training, or education may testify in the form of an opinion or otherwise if:

(a) The expert's scientific, technical, or other specialized knowledge will help the trier of fact to understand the evidence or to determine a fact in issue; (b) The testimony is based on sufficient facts or data; (c) The testimony is the product of reliable principles and methods; and

(d) The expert has reliably applied the principles and methods to the facts of the case" [4].

Apparently, the US Supreme Court acted rightly, putting aside the general recognition of scientific data as a criterion for evaluation of evidence, obtained on their basis. However, is the problem of recognition the results of polygraph testing as judicial evidence resolved?

In our opinion, the answer to the above question can be only negative. The reason for such an assertion is that, in regard to the circumstances, which the court should take into account, according to the Daubert standard and the Federal Rules of Evidence, the doctrine of polygraph testing does not provide an unambiguous explanation.

As it is known, the basis of polygraph testing is the socalled "psychophysiological phenomenon". Its essence consists in appearance of more intense reactions of tested person on certain questions, asked by the polygraph operator. It is the evidence, that for some reason, these questions are more significant for the tested person, than the others. Investigating the differences between reactions to control and test questions, the polygraph operator makes judgments about the falsity or truthfulness of the testee's answers, 
about the hidden information, about his involvement or non-participation in a certain case, etc.

But according to the literature, the change in physiological reactions of tested person can be caused by a variety of other emotional factors, including stress, confusion, anger, etc. Moreover, polygraph testing itself causes fear and anxiety. In this regard, some authors compare the accuracy of this testing with the accuracy of tossed coin, and propose to eject the use of polygraph to the sphere of parapsychology along with phrenology and chirognomy [5, p. 75-77]. The above estimation of the reliability of polygraph studies was confirmed during the experiment, involving polygraph operators, which had different levels of polygraph testing experience. According to the professor of the University of Alabama, Charles Ford, the best specialist made mistakes in $18 \%$ of cases, having taken the truth for a lie, and the experts, who showed the worst results, were at fault in 55\% of cases. The author noted that the most experienced polygraph experts ( 8 years of experience) had the highest percentage of false positive results [6, p. 320], i.e. they took the truth for a lie.

As follows from the Daubert standard, evaluation of the results of polygraph testing requires the court to verify that the data, on the basis of which these results are obtained, are verifiable. Meanwhile, in the doctrine of polygraph testing, reliable methods of verification have not been developed, despite the fact that field studies were carried out for this purpose. The subjects of such researches were real, occurring incidents. The investigations by analogy (laboratory researches) were also carried out, the subjects of which were artificially created situations.

Professor of the University of California Paul Ekman, analyzing the above investigations, writes: "Field and analog studies mirror each other's strengths and weaknesses. In field studies the suspects really do care about the polygraph test outcome, and therefore strong emotions are likely. Another strength is that the right kinds of people are studied - real suspects, not college freshmen.

The weakness of field studies is the ambiguity about ground truth. Certainty about ground truth is the chief strength of analog studies; it is easy to know, since the researcher arranges who will lie and who will be truthful. Their weakness is that because the "suspects" usually have little or nothing at stake, the same emotions are not likely to be aroused. Also, the people tested may not resemble the kinds of people who most often actually take the polygraph test".

To confirm the expressed opinions, the author cites an extract from the conclusion about scientific evidence of the accuracy of polygraph tests' results, presented by the Bureau of Technological Assessment to the US Congress in 1983: "using the criminal justice system outcomes, polygraph examinations may appear to have a high number of [disbelieving-the-truth mistakes] in the case of acquittals, or [believing-a-lie mistakes] in the case of dismissals" [7, p. 208-209]. Twenty years later, the same problems of polygraph testing accuracy were reflected in the report of the Committee to Review the Scientific Evidence on the Polygraph (2003) in the form of the following statement: "Almost a century of research in scientific psychology and physiology provides little basis for the expectation that a polygraph test could have extremely high accuracy. Although psychological states often associated with deception (e.g., fear of being judged deceptive) do tend to affect the physiological responses that the polygraph measures, these same states can arise in the absence of deception. Moreover, many other psychological and physiological factors (e.g., anxiety about being tested) also affect those responses. Such phenomena make polygraph testing intrinsically susceptible to producing erroneous results"'[8, p. 2].

In addition, this report contains the statement, that the countermeasures, using during the testing, have long been recognized as a distinct threat to the validity and utility of the polygraph [8, pp. 139-140, 216].

In the light of the above circumstances, legislative establishment of the limits of using the polygraph testing results by the US military courts in the Military Rules of Evidence of 1991 acquires particular importance. In this law, the rule 707 is devoted to the issue of using the results of polygraph testing ("Polygraph Examinations"):

(a) Prohibitions. Notwithstanding any other provision of law, the results of a polygraph examination, the opinion of a polygraph examiner, or any reference to an offer to take, failure to take, or taking of a polygraph examination, shall not be admitted into evidence.

(b) Statements Made During a Polygraph Examination. Nothing in this section is intended to exclude from evidence statements made during a polygraph examination which are otherwise admissible [9].

The above rule was the subject of consideration by the US Supreme Court in terms of its constitutionality, on the complaint of the convicted Schaeffer.

The US Supreme Court came to the conclusion that rule 707: 1) does not violate the constitutional right to defense; 2) provides for the use of only reliable evidence, and with respect to the reliability of evidence, obtained with the use of polygraph, the scientific community remains extremely polarized; 3 ) is aimed at preserving of the main function of court and jurors - to evaluate the reliability of the presented evidence independently, while the evidence, obtained with the use of polygraph can significantly affect the 
Helix Vol. 8(4): 3535- 3538

views of the jury and reduce their function to zero; 4) allows to eliminate from judicial proceedings the litigations about the use of polygraph as a source of evidence, which pose a threat that the attention of jurors will be diverted from their main function: the solution of question about the guiltiness or innocence of the defendant [10].

\section{Conclusion}

The study of experience of the United States in legislative regulation of evidence use, obtained on the basis of scientific data, allows to suggest that the question about the evidentiary value of polygraph test results has found its unique solution only in military courts, and it consists in the restriction of use of these results as judicial evidence.

Taking into account, that neither the doctrine of polygraph testing, nor the legal precedents create neutralization mechanism for the factors, which cast doubt on the accuracy of the polygraph test results, the optimum solution is to set limits on their use, only in the framework of pre-trial proceedings, and only as reference information, required for the nomination of investigative leads, and planning of investigative and other procedural actions, aimed at verifying the testimonies of participants in criminal proceedings, in case of doubts about their completeness and reliability.

\section{References}

1. Frye v. United States // https://www.coursehero.com/file/23557721/Frye (accessed 7 March 2018).

2. H.R. 5463 (93rd): Federal Rules of Evidence // https://www.govtrack.us/congress/bills/93/hr5463/tex $\mathrm{t}$ (accessed 7 March 2018).

3. Daubert v. Merrell Dow Pharmaceuticals, ins. 509 U.S. 579 (1993) // https://www.law.cornell.edu/supct/html/92-

102.ZO.html (accessed 7 March 2018).

4. Federal Rules of Evidence. December 1, $2016 / / \mathrm{U}$. S. Government Publishing Office Washington: 2016. P. 41.

5. Langan M. L. The Art of Deception: Polygraph Lie Detection // Gray areas. 1995. V.4. \# 1. Pp. 75-77.

6. Ford C.V. Lies! Lies! Lies!!! The Psychology of Deceit. M.: Eksmo, 2013. P. 400 (in Russian).

7. Ekman P. Telling lies. Clues to deceit in the marketplace, politics, and marriage. N-Y.: W.W. Norton \& Co., 1992. P. 366.

8. The Polygraph and Lie Detection // Committee to Review the Scientific Evidence on the Polygraph. Division of Behavioral and Social Sciences and Education. Wash.: DC: The National Academies Press. 2003. P. 416.
9. The Military Rules of Evidence // https://www.mcmilitarylaw.com/military-rules-ofevidence.html (accessed 7 March 2018).

10. United States v. Scheffer, 523 U.S. 303 (1998) //

https://supreme.justia.com/cases/federal/us/523/303/c ase.html (accessed 7 March 2018). 